\title{
Clinical and epidemiological aspects of patients with cow's milk allergy followed in a public health reference center in central Brazil
}

\author{
Germana Pimentel Stefani ${ }^{*}$, João Bosco Siqueira Junior ${ }^{2}$, Ludimila Porto L Nunes ${ }^{1}$, Isabela De Oliveira Lima', \\ Claudia Cantelli Daud Bordin ${ }^{1}$
}

From 3rd WAO International Scientific Conference (WISC) 2014

Rio de Janeiro, Brazil. 6-9 December 2014

\section{Background}

The prevalence of cow's milk allergy (CMA) has increased in last decades. The disease affects especially young infants and their clinical presentation can be diverse, often associated with comorbidities. The diagnosis is essentially based on clinical aspects and challenge tests. Its treatment demands strict adherence to elimination diet, with avoidance of milk protein and, for infants, the use of special hypoallergenic formulas. The increase in demand for these formulas, costly to the Public Health System, makes it necessary to better characterize the target population of assistance programs.

\section{Methods}

This is a descriptive, observational, cross-sectional study based on secondary data collected from a standardized first consultation's form, regarding clinical and epidemiological aspects of patients who have requested special formulas due to previous diagnosis of cow's milk allergy and were referred to a Municipal Health Centre of Food Allergy in Central Brazil.

\section{Results}

Between January 2011 and May 2012, 449 patients (55\% male) were admitted. The mean age at admission was 11.34 months $( \pm 8.03)$, while the average age of onset of symptoms suggestive of food allergy was 3.87 months ( \pm 4.19$)$. Almost $90 \%$ of the patients presented symptoms during the first year of life. Extensively hydrolyzed formulas were the mostly requested. Absolute predominance of notIgE-mediated cases was noted $(88,4 \%)$, typically with late presentation and preponderance of digestive (91.3\%) and systemic (33.4\%) symptoms, with rare anaphylactic reactions (03 cases). Children under one year have had significantly more digestive symptoms than older infants. At admission time, $24.6 \%$ infants younger than 6 months were underweight ( $\mathrm{z}<-2$ weight-for-age score). Despite the family history of atopy in up to $75 \%$ of cases, over $80 \%$ of children had consumed milk with intact cow's milk protein at weaning. Half the patients using soy formulas have started their consumption before 6 months of life. The proportion of infants with the diagnosis of Gastroesophageal Reflux Disease was $68 \%$, and $90 \%$ of them were taking acid suppressors drugs.

\section{Conclusions}

The better characterization of the population seeking special formulas allows the generation of public health interventions in the fields of prevention, diagnosis and treatment, and also optimize overall patient care combined with effectiveness and lower costs.

\section{Authors' details \\ ${ }^{1}$ Secretaria Municipal De Saúde De Goiânia, Brazil. ${ }^{2}$ Federal University of Goias, Brazil.}

Published: 8 April 2015

\section{doi:10.1186/1939-4551-8-S1-A73}

Cite this article as: Stefani et al:: Clinical and epidemiological aspects of patients with cow's milk allergy followed in a public health reference center in central Brazil. World Allergy Organization Journal 2015 8(Suppl 1): A73.

${ }^{1}$ Secretaria Municipal De Saúde De Goiânia, Brazil

Full list of author information is available at the end of the article 